\section{Association between a Blood Group and Butterfat Production in Dairy Cattle}

MANY workers have examined the possibility that the polymorphism found in cattle blood groups may be due in part to their association with production characters. Various associations have been found ${ }^{1-4}$, but the most striking one is between fat percentage and the $B$ allele $B B_{1} Y_{3} D^{\prime}$ (refs. 5-7).

This study was carried out to see if such an association could also be found in our herds. Butterfat and milk yields were taken on a 305-day lactation and were recorded in pounds from 290 first lactations in a Holstein-Friesian herd at the Emmons Blaine, jun., Experimental Frrm, Lake Mills, Wisconsin, with the co-operation of Dr. W. J. Tyler. The total milk yield, and percentage and total butterfat, were compared with the following blood factors, $A, B, Y_{2}, F, V, J, S, U_{2}, L, Z$ and two phenogroups at the $B$ locus $B O_{1} Y_{2} D^{\prime}$ and $G Y_{2} E^{\prime}{ }_{1}$. A general least squares method was used to analyse the data on an IBM 650 electronic computer. The data were divided into seven groups representing seven sire lines, and a within-group analysis was carried out.

In the regression analysis, all economic factors were treated as dependent variables; the blood types were treated as independent variables. A total regression equation was obtained for each of the dependent variables on all the blood types. The data were then divided into seven groups representing the seven sire-lines. Simple correlations were obtained within each line and a test of heterogeneity among lines was made.

Table 1. Partiat Regression Comfichents of Economo factors on BLOOD GROUP GENES

\begin{tabular}{|c|c|c|c|}
\hline $\begin{array}{l}\text { Blood group } \\
\text { genes }\end{array}$ & $\begin{array}{l}\text { Total milk yield (lb.) } \\
b \pm S_{b}\end{array}$ & $\underset{b \pm S_{b}}{\text { Butterfat } \%}$ & $\begin{array}{c}\text { Total butterfat (lb.) } \\
b \pm S b\end{array}$ \\
\hline $\begin{array}{l}B^{B O_{1}} Y_{2} D^{\prime} \\
B^{G} Y_{2} E_{1}^{\prime}\end{array}$ & $\begin{array}{r}-967 \cdot 18 \pm 1,430 \cdot 4 \\
251 \cdot 08 \pm 1,019 \cdot 9\end{array}$ & $\begin{array}{l}0 \cdot 332 \pm 0 \cdot 136 * \\
0.058 \pm 0 \cdot 114\end{array}$ & $\begin{array}{r}-12 \cdot 28 \pm 35 \cdot 68 \\
1 \cdot 85 \pm 29 \cdot 83\end{array}$ \\
\hline
\end{tabular}

As shown in Table 1, a significant effect of the $B$ phenogroup $B O_{1} Y_{2} D^{\prime}$ on butterfat percentage was found. The percentage butterfat of cows with this allele (the great majority being heterozygous) was 0.33 higher than in those lacking it. This is the fourth population of cattle in which such a significant association was found. Heterogeneity among lines was non-significant $(P>0 \cdot 5)$. No other significant associations were found.

With the amount of evidence accumulated at present, there is little doubt that the statistically significant associations found by various workers between blood groups and economic characters in dairy cattle are real and have some biological meaning. The best authenticated relationship found so far is that between fat percentage and the $B$ phenogroup $B O_{1} Y_{2} D^{\prime}$. This association is most likely pleiotropic. We can rule out linkage, as one would not expect to find a specific relationship in both European and American herds of different breeds. Unless linkage was absolute, recombination would have randomized this association with respect to other phenogroups; furthermore, Neimann-Sørensen and Robertson? wore unable to find linkage in their studies.

Differences in the effect of the $B$ phenogroup, $B O_{1} Y_{2} D^{\prime}$, on butterfat production found by Rendel ${ }^{6}(0 \cdot 16$ per cent) and by Neimann-Sørensen and Robertson? $(0.06$ per cent) and that found in our study $(0.33$ per cent) might be expected since many factors are probably involved in butterfat production. Environmental and genetic variation in these factors could well account for the differences.

It seems likely that some balance mechanism must be operating to maintain the high degree of polymorphism in cattle blood group genes. It is highly probable that the associations described here are closely connected with this balance mechanism.

From a practical point of view, the use of blood groups as an aid to artificial selection in dairy cattle is doubtful at present. The allele $B B O_{1} Y, D^{\prime}$ seems to have a definite beneficial effect on fat percentage and so far is the only one which could be of much value for selection purposes.

This work was supported in part by U.S. Public Health Service grant $E-1643$ from the Institute of Allergy and Infectious Diseases.

Department of Genetics,

P. M. Conneally

W. H. STONE

University of Wisconsin, Madison.

${ }^{1}$ Dunlop, A. A., J. Dairy Sci., 34, 154 (1951).

${ }^{2}$ McClure, T. J., Nature, 170, 327 (1952).

3 Nair, P. G., Ph.D. thesis, University of Ohio (1956).

- Tolle, A., Proc. VI Int. Blood Group Cong., Munich, 40 (1959). Andresen, E., Hozgaard, N., Moustgaard, J., and Neimann-Sørensen, A.,
Proc. VI Int. Blood Group Cong., Munich, 24 (1959).

' Rendel, J., Zeitschr. Tierz. u. Zucht. Biol., 75, 97 (1961).

'Neimann-Sørensen, A., and Robertson, A., Acta Agric. Scand., 11, 163 (1961).

\section{VIROLOGY}

\section{Freeze-drying of Certain Viruses}

IT is important that a virus reference laboratory be able to hold viruses in the infectious state for long periods and to transmit them long distances. We have experienced difficulty with some newly isolated viruses of the respiratory tract. Some preparations of para-influenza viruses and rhinoviruses have become non-infectious after being frozen at below $-60^{\circ} \mathrm{C}$ in the presence of 2 per cent bovine plasma albumen or 2 per cent calf serum respectively for a year or more; the former viruses rapidly become non-infectious at room temperature ${ }^{1}$ and so have been transported in the frozen state or as infected tissue cultures. In earlier experiments virus was preserved by freeze-drying, but much infectivity was lost. In recent experiments viruses seem to have been better stabilized, and the results are reported here.

Virus in the form of a tissue culture fluid was mixed with an equal volume of stabilizer and $0.1-\mathrm{ml}$. aliquots of the mixture were put into ampoules. The ampoules were dried for a total of about a day on an Edwards model $5 P S$ centrifugal freeze-drier and were sealed at a final vacuum of less than 20 torr. The ampoules were usually stored in a domestic refrigerator and the presence of a vacuum was confirmed with a high-frequency tester before they were opened for use. The viruses were titrated by limit dilution endpoints in roller tube cultures using standard methods ${ }^{1,2}$. Para-influenza viruses were titrated in rhesus monkey kidney cells and detected by haemadsorption. Enteroviruses and rhinoviruses were titrated in these cells or human diploid cell strains ${ }^{3}$ as was possible or convenient. Respiratory syncytial virus was titrated in stationary cultures of HeLa cells. It appeared that para-influenza viruses suspended in tissue culture medium could be stabilized by the addition of an equal volume of skimmed milk. Table 1 shows that all 4 prototype strains were successfully dried, and although there was a drop of $2 \log _{10}$ units in the titre during freezedrying the residual infectivity was unchanged after 2 weeks of storage at room temperature or several months at $4^{\circ} \mathrm{C}$. Several strains of respiratory syncytial virus have been successfully dried by this technique. The titre dropped by about $2 \log _{10}$ units during freezing and drying and ampoules retained their infectivity for 16 months at refrigerator temperature. Attempts to freezedry respiratory syncytial virus in other media have been unsuccessful ${ }^{4}$.

Rhinoviruses in the form of tissue culture fluids containing about 2 per cent calf serum in Eagle's medium were mixed with an equal volume of 10 per cent dextran (Benger's 'Dextraven') and 10 per cent glucose in distilled water. There was little or no drop in the titre of most $M$ rhinoviruses when they were dried from this solution, but the titre of $H$ rhinoviruses dropped, often by as much as $2 \log _{10}$ units. Although this difference between the two 